\title{
Self-Assembly of Gold Nanoparticles as Colloidal Crystals Induced by Polymerization of Amphiphilic Monomers
}

\author{
I. A. Zucchi ${ }^{\dagger}$ C. E. Hoppe, ${ }^{*},+*$ M. J. Galante, ${ }^{\dagger}$ R. J. J. Williams, ${ }^{*}, \dagger$ \\ M. A. López-Quintela, ${ }^{\ddagger}$ L. Matějka, ${ }^{\S}$ M. Slouf, ${ }^{\S}$ and J. Pleštil ${ }^{\S}$ \\ Institute of Materials Science and Technology (INTEMA), University of Mar del Plata and National \\ Research Council (CONICET), J. B. Justo 4302, 7600 Mar del Plata, Argentina, Laboratory of \\ Magnetism and Nanotechnology, Department of Physical Chemistry, University of Santiago de \\ Compostela, Santiago de Compostela, Spain, and Institute of Macromolecular Chemistry, \\ Academy of Sciences of the Czech Republic, Heyrovsky Sq. 2, 16206 Prague 6, Czech Republic
}

Received February 29, 2008; Revised Manuscript Received May 5, 2008

\begin{abstract}
The self-assembly of inorganic nanoparticles (NPs) into hierarchical structures on different length scales is one of the main aspects of "bottom-up" approaches to create materials with specific electronic, optical, or magnetic properties. We report a new procedure to generate and stabilize colloidal crystals formed by gold NPs during a polymerization reaction, leading to an amphiphilic physical gel. Dodecanethiol-stabilized gold NPs with an average diameter of $2 \mathrm{~nm}$ were synthesized and dissolved $(0.15 \mathrm{wt} \%)$ in a stoichiometric mixture of diglycidylether of bisphenol A (DGEBA) and dodecylamine (DA). The polymerization of DGEBA with DA was carried out at $100{ }^{\circ} \mathrm{C}$ leading to a linear polymer that very slowly generated an amphiphilic physical gel by the self-assembly of dodecyl chains. The formation of the physical gel was followed by rheometry and its structure investigated by SAXS. In the course of this polymerization, gold NPs were phase-separated generating colloidal crystals with dimensions varying from tens to hundreds of nanometers (TEM) and exhibiting a 3D hexagonal close-packed (HCP) structure (SAXS). The size of the gold NPs forming the colloidal crystals was about twice the original size, meaning that a coalescence process took place. This was confirmed by the increase in the intensity of the plasmon band in UV-visible absorption spectra. Partitioning and irreversible adsorption of large colloidal particles at the air-polymer interface were observed, leading to highly ramified fractal structures. This was explained by the high energy needed to remove large colloidal particles attached at the interface. The polymer precursors used in the present study may, in principle, be employed for different kinds of NPs stabilized by hydrophobic chains to generate dispersions of colloidal crystals in polymer gels or percolating fractal structures at the air-polymer interface.
\end{abstract}

\section{Introduction}

The self-assembly of inorganic nanoparticles (NPs) into hierarchical structures on different length scales is one of the main aspects of "bottom-up" approaches for device fabrication. ${ }^{1-7}$ Potential applications of assemblies of metallic NPs can be found in the fields of catalysis, ${ }^{6,8}$ optics, ${ }^{4}$ electronics, ${ }^{9}$ etc. Some recent works provide specific examples of possible applications. For example, Uhlenhaut et al. ${ }^{10}$ described the synthesis of elastomeric films containing micrometric aggregates of gold NPs. These materials behaved as reversible color systems as a result of kinetically controlled particle dispersions states. Moreover, due to the elastic properties of the matrix, dichroic states could be generated that could be reversibly transformed to isotropic states through swelling. The controlled liquid-liquid or air-liquid interfacial self-assembly of NPs has received considerable interest due to the potential technological applications. ${ }^{11-18}$ In these procedures, morphology and extent of self-organization of the NPs at the interface are controlled by a combination of different physicochemical variables (surface tension, evaporation kinetics, electrostatic forces, etc.). ${ }^{17,19} \mathrm{~A}$ variety of structures such as membranes, ${ }^{12}$ magnetic colloids, ${ }^{14}$ and antistatic layers ${ }^{17}$ were fixed by cross-linking after the self-assembly process. Trapping of tin oxide NPs in thin surface layers by self-assembly at the air-liquid interface allowed obtaining antistatic coatings with excellent conductive properties, which were attributed to the

\footnotetext{
* To whom correspondence should be addressed. E-mail: hoppe@ fi.mdp.edu.ar (C.E.H.); williams@ @i.mdp.edu.ar (R.J.J.W.).

University of Mar del Plata and National Research Council (CONICET).

University of Santiago de Compostela.

$\S$ Academy of Sciences of the Czech Republic.
}

formation of localized clusters on the surface. ${ }^{18}$ Zhang et al. ${ }^{20}$ showed that dendritic gold clusters formed onto a polyelectrolyte multilayer lead to the formation of superhydrophobic surfaces of high stability. In summary, nanocomposites based on metallic NPs clusters embedded in or present at the surface of polymer matrices constitute promising materials for advanced technologies.

In this study, we will show the use of polymerization-induced phase separation (PIPS) to produce the self-assembly of gold nanoparticles in a cross-linked polymer matrix. By this approach, the formation of 3D colloidal crystals and their immobilization in the final cross-linked polymer can be attained through a onestep and one-pot procedure.

When a polymerization is carried out in the presence of a modifier (a rubber, a thermoplastic polymer, a liquid crystal, etc.), a phase separation process usually takes place leading to different types of morphologies that depend on the initial composition and reaction conditions. PIPS is used in practice to synthesize a set of useful materials such as high-impact polystyrene (HIPS), ${ }^{21}$ rubber-modified thermosets, ${ }^{22}$ thermoplastic - thermoset blends, ${ }^{23}$ polymer-dispersed liquid crystals, ${ }^{24}$ thermally reversible light scattering films, ${ }^{25,26}$ and nanostructured thermosets. ${ }^{27} \mathrm{~A}$ recent simulation showed that a similar situation may take place for a solution of NPs in a reactive solvent. ${ }^{28}$ Polymerization of the solvent may induce the phase separation of the NP-rich phase. Once the NPs become concentrated, they can self-assemble into organized domains that are trapped in the generated polymer. We have recently shown that a solution of a polyhedral oligomeric silsesquioxane (POSS) in epoxy precursors could be phase separated in the course of polymerization, yielding, under particular conditions, 

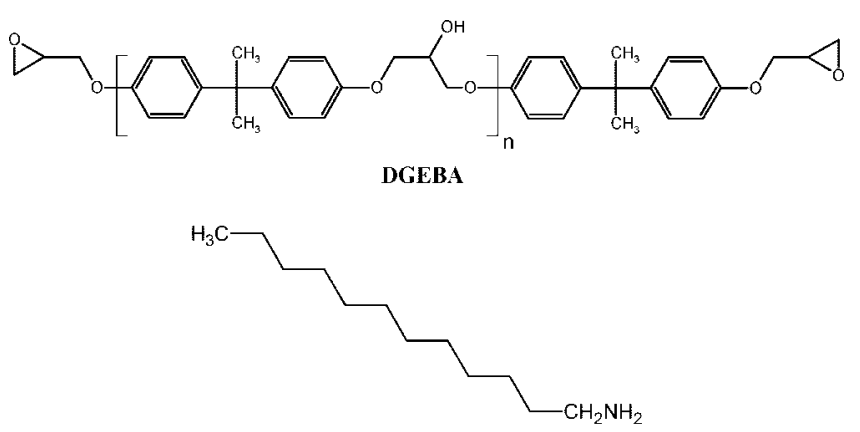

DA

Figure 1. Chemical structures of DGEBA and DA.

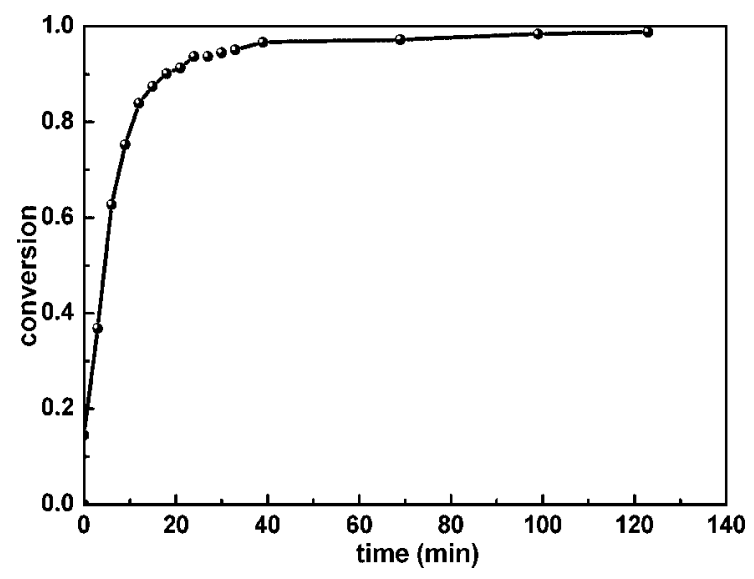

Figure 2. Conversion of epoxy groups determined by NIR spectroscopy as a function of reaction time at $100{ }^{\circ} \mathrm{C}$.

a crystalline phase dispersed in the epoxy matrix. ${ }^{29}$ The aim of the present study was to investigate if metallic NPs could be phase separated and self-assembled in the course of the polymerization of a reactive solvent, yielding some kind of ordered arrays trapped in the polymer.

The particular system investigated in this study was composed of dodecanethiol-stabilized gold NPs dissolved in a reactive solvent constituted of stoichiometric amounts of diglycidylether of bisphenol A (DGEBA) and dodecylamine (DA). We will show that the DGEBA-DA reaction forms a linear polymer that undergoes a nanostructuration process by the self-assembly of dodecyl chains. The phase separation and self-assembly of gold NPs induced by polymerization of the reactive solvent is reported in the following sections.

\section{Experimental Section}

Materials. The diepoxy monomer was based on diglycidyl ether of bisphenol A (DGEBA, DER 332, Dow), with a mass per mole of epoxy groups equal to $174.3 \mathrm{~g} / \mathrm{mol}(n=0.03$ in the chemical structure shown in Figure 1). The selected amine was dodecylamine (DA, 98 wt \%, Aldrich), a crystalline solid with a melting temperature of $27-29{ }^{\circ} \mathrm{C}$ (chemical structure shown in Figure 1). Dodecanethiol, hydrogen tetrachloroaurate(III) trihydrate $\left(\mathrm{HAuCl}_{4} \cdot 3 \mathrm{H}_{2} \mathrm{O}, \geq 49 \mathrm{wt} \%\right.$ as $\left.\mathrm{Au}\right)$, tetraoctylammonium bromide, and sodium borohydride were purchased from Aldrich and used as received.

Synthesis of Dodecanethiol-Coated Gold Nanoparticles. They were synthesized using a modification of the Brust-Schiffrin method. ${ }^{30}$ Briefly, $1.1 \mathrm{mmol}$ of $\mathrm{HAuCl}_{4} \cdot 3 \mathrm{H}_{2} \mathrm{O}$ was dissolved in a solution of tetraoctylammonium bromide in toluene. After stirring overnight, dodecanethiol (DDT) was added in a molar ratio of 0.9 with respect to gold. An excess of freshly prepared sodium borohydride aqueous solution was then added

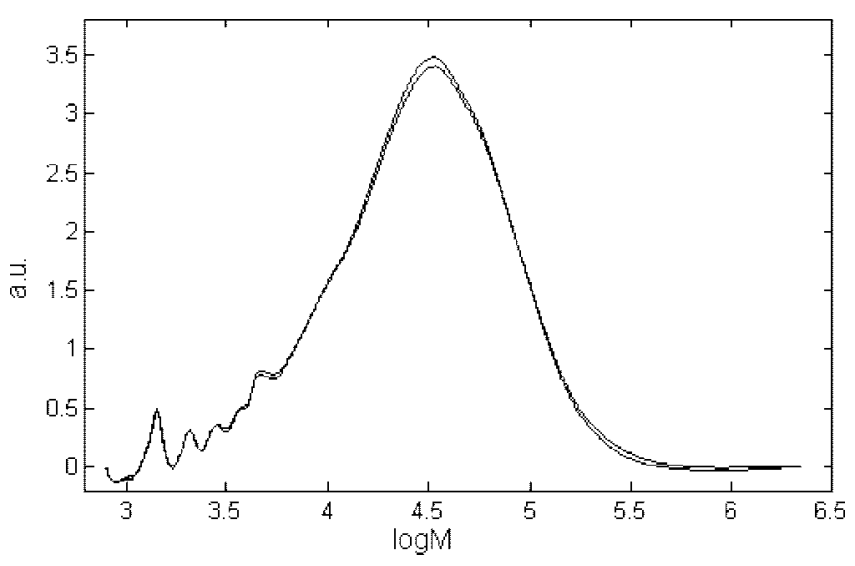

Figure 3. Distribution of molar masses of the epoxy-amine linear polymer after $4 \mathrm{~h}$ reaction at $100{ }^{\circ} \mathrm{C}$, obtained by SEC relative to PS standards (superposition of two runs).

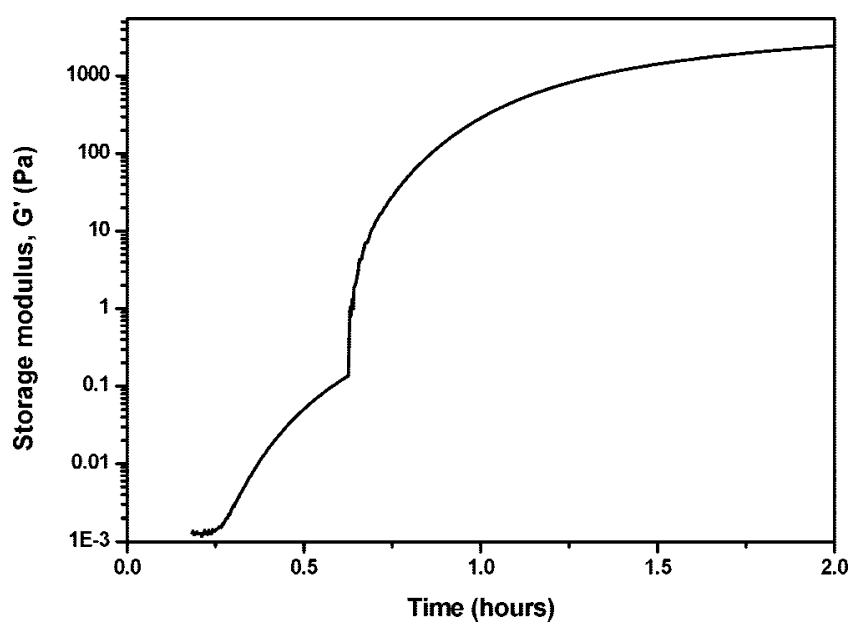

Figure 4. Evolution of the dynamic shear storage modulus $\left(G^{\prime}\right)$ of a DGEBA-DA formulation during the first $2 \mathrm{~h}$ reaction at $100{ }^{\circ} \mathrm{C}$.

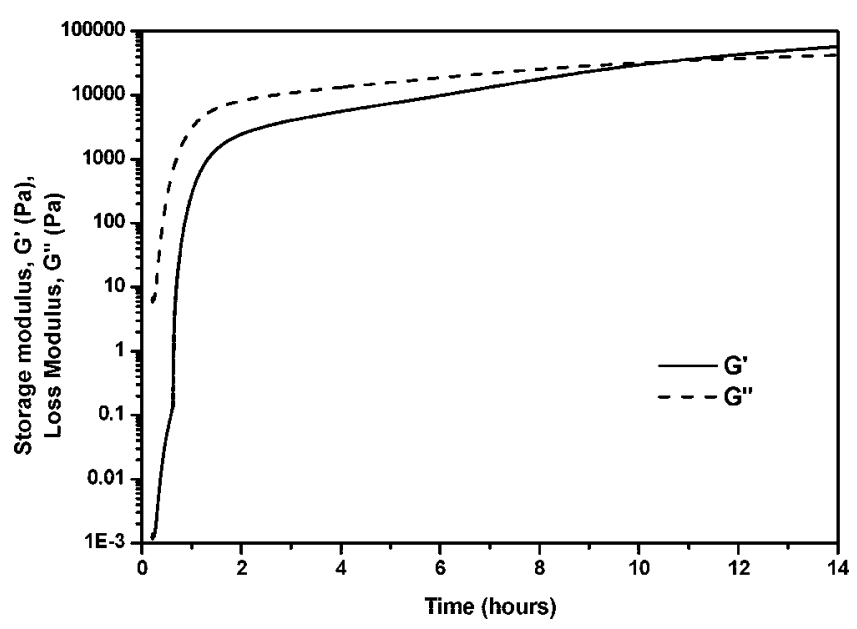

Figure 5. Evolution of the storage $\left(G^{\prime}\right)$ and loss modulus $\left(G^{\prime \prime}\right)$ during the prolonged heating of the DGEBA-DA formulation at $100{ }^{\circ} \mathrm{C}$.

as reducing agent. The as synthesized DDT-coated gold NPs were separated from unattached DDT by precipitation with ethanol (in a volume ratio respect to toluene solution of 7:1), followed by centrifugation $(8000 \mathrm{rpm})$. The wet product was dried at $40{ }^{\circ} \mathrm{C}$ and stored as a waxy solid at room temperature.

Polymerization-Induced Phase Separation. DDT-coated gold NPs were dispersed in tetrahydrofuran (THF) at concentrations close to $3.5 \mathrm{mg} / \mathrm{ml}$. The solution was blended with 


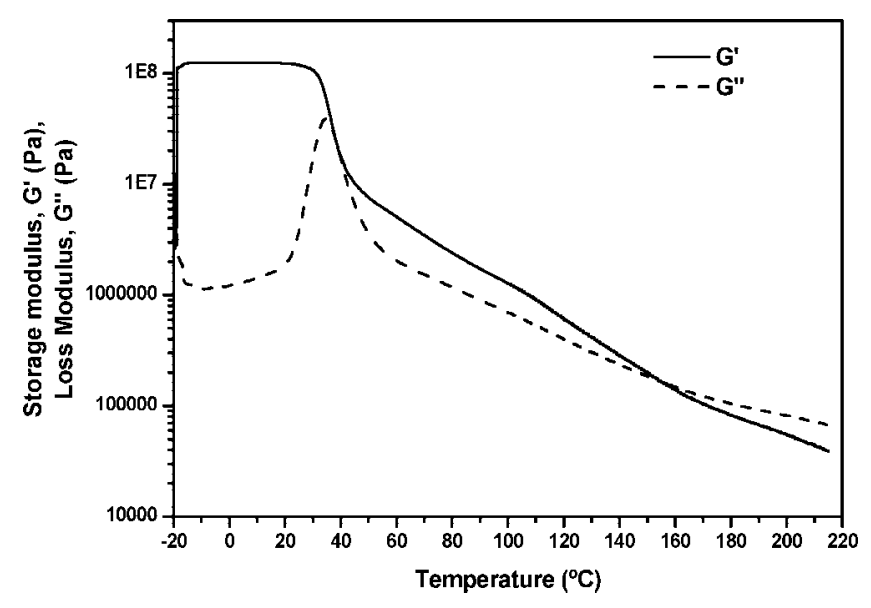

Figure 6. Evolution of the storage $\left(G^{\prime}\right)$ and loss modulus $\left(G^{\prime \prime}\right)$ during a thermal scan at $1{ }^{\circ} \mathrm{C} / \mathrm{min}$ of a sample previously heated during $14 \mathrm{~h}$ at $100{ }^{\circ} \mathrm{C}$, stored for 2 days at room temperature, and cooled to -20 ${ }^{\circ} \mathrm{C}$.

dodecylamine in the amount necessary to obtain a $0.15 \mathrm{wt} \%$ concentration of DDT-coated gold NPs in the final material. After THF evaporation, a stoichiometric amount of DGEBA was added with continuous stirring at $100{ }^{\circ} \mathrm{C}$. The resulting solution was strongly colored but optically homogeneous. Samples of about $1.8 \mathrm{~mm}$ thickness were cast on a silicon mold, heated in an oven at $100{ }^{\circ} \mathrm{C}$ for $14 \mathrm{~h}$, and cooled to room temperature.

The neat DGEBA-DA polymer was obtained following a similar schedule.

Characterization. The size distribution of as-synthesized gold NPs was determined using a Philips CM-12 transmission electron microscope (TEM) operated at an accelerating voltage of $100 \mathrm{kV}$. Samples were prepared by dropping $6 \mu \mathrm{L}$ of a dispersion of the particles on a copper grid coated with Formvar and a carbon film. The percentage of gold and DDT in the synthesized NPs was determined by thermogravimetry (PerkinElmer, TGA 7). Dynamic scans were performed under oxygen flow at $10^{\circ} \mathrm{C} / \mathrm{min}$ between 50 and $800{ }^{\circ} \mathrm{C}$. The plasmon band of the solution of NPs in THF was recorded with an UV1601PC-Shimadzu spectrophotometer. Samples were placed in a $1 \mathrm{~cm} \times 1 \mathrm{~cm} \times 3 \mathrm{~cm}$ quartz cell and spectra recorded at room temperature. The same device was used to determine the plasmon band of the gold NPs embedded in the epoxy matrix. A special cell for solid samples was used for this purpose.

The molar mass distribution of the neat epoxy polymer obtained after $3 \mathrm{~h}$ reaction at $100{ }^{\circ} \mathrm{C}$ was analyzed by size exclusion chromatography (SEC, Waters 1525). A set of seven Styragel columns (Waters, $7.8 \mathrm{~mm} \times 300 \mathrm{~mm}$ ) was used, with fractionation limits: $1 \times 10^{3}, 5 \times 10,{ }^{3} 2 \times 10^{4}, 3 \times 10^{4}, 6 \times$ $10^{5}, 4 \times 10^{6}$, and $1 \times 10^{7} \mathrm{~g} / \mathrm{mol}$. The detector was a differential refractometer (Waters $2414-410$, at $30^{\circ} \mathrm{C}$ ). THF was employed as a carrier with a flow rate of $1 \mathrm{~mL} / \mathrm{min}$. The calibration curve was obtained using nine PS standards (Shodex standard SM105, Showa Denko). Individual peaks of low-molar species were assigned employing matrix-assisted laser desorption-ionization time-of-flight mass spectrometry (MALDI-TOF MS). Measurements were performed with a Bruker Autoflex device equipped with a pulsed nitrogen laser. The matrix was 1,8-dihydroxy$9(10 \mathrm{H})$ anthracenone (dithranol), and the sample was prepared from a THF solution of a mixture of equal parts by weight of the epoxy-amine polymer, dithranol, and NaI. Spectra were obtained in the linear positive mode.

The solubility of the neat epoxy polymer at different times during the heating at $100{ }^{\circ} \mathrm{C}$ was investigated using a variety of solvents: THF, dichloromethane, chloroform, dimethylfor-

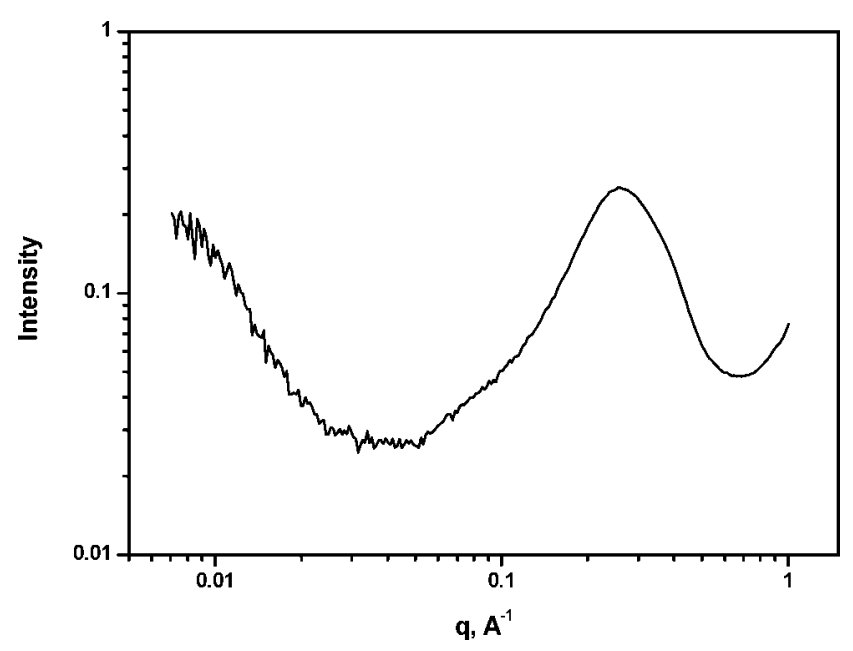

Figure 7. SAXS spectrum of a DGEBA-DA sample heated for $14 \mathrm{~h}$ at $100{ }^{\circ} \mathrm{C}$ and recorded at room temperature.

mamide (DMF), dimethylsulfoxide (DMSO), ethyleneglycol, p-xylene, cyclohexane, heptane, acetone, THF/ethanol solution, and $\mathrm{LiCl} / \mathrm{DMF}$ solution $(0.1 \mathrm{M}$ in $\mathrm{LiCl})$. Solubility tests were performed by placing about $150-200 \mathrm{mg}$ of sample in $10 \mathrm{~mL}$ test tubes filled with $3 \mathrm{~mL}$ of the corresponding solvent.

Middle-infrared spectroscopy (MIR, Genesis II, Mattson) was employed to analyze the conformation of alkyl chains of DA in the neat epoxy polymer. Measurements were carried out using $\mathrm{KBr}$ disks impregnated with the epoxy polymer. The same instrument, provided with a heated transmission cell (HT-32, Spectra Tech) with quartz windows (32 $\mathrm{mm}$ diameter) and a programmable temperature controller (Omega, Spectra Tech, $\Delta T= \pm 1^{\circ} \mathrm{C}$ ), was used in the near-infrared mode (NIR) to follow the consumption of epoxy groups during reaction with DA at $100{ }^{\circ} \mathrm{C}$. The height of the absorption band at $4530 \mathrm{~cm}^{-1}$ with respect to the height of a reference band at $4621 \mathrm{~cm}^{-1}$ was monitored as a function of reaction time. ${ }^{26,31-33}$

The evolution of the storage $\left(G^{\prime}\right)$ and loss modulus $\left(G^{\prime \prime}\right)$ with reaction time at $100{ }^{\circ} \mathrm{C}$ was followed using an Anton Paar rheometer (model Physica MCR-301) provided with a CTD 600 thermo chamber. A parallel-plate configuration (diameter $D=25$ $\mathrm{mm}$, gap $H=1.3 \mathrm{~mm}$ ) was used in oscillatory mode with a $1 \%$ amplitude at a frequency of $1 \mathrm{~Hz}$. Temperature scans of final samples were performed at $1{ }^{\circ} \mathrm{C} / \mathrm{min}$ from -20 to $220{ }^{\circ} \mathrm{C}$.

The glass transition temperature $\left(T_{\mathrm{g}}\right)$ was determined by differential scanning calorimetry (DSC, Perkin-Elmer DSC7) from onset values of the change in specific heat in heating scans performed at $10{ }^{\circ} \mathrm{C} / \mathrm{min}$.

The nanostructuration produced in the neat epoxy polymer and in the composite with gold NPs was investigated using small-angle X-ray scattering (SAXS). Measurements were performed using a pinhole camera (Molecular Metrology SAXS System) attached to a microfocused X-ray beam generator (Osmic MicroMax 002) operating at $45 \mathrm{kV}$ and $0.66 \mathrm{~mA}$ (30 $\mathrm{W})$. The camera was equipped with a multiwire, gas-filled area detector with an active area diameter of $20 \mathrm{~cm}$ (Gabriel design). Two experimental setups were used to cover the $q$ range of $0.007-1.1 \AA^{-1}$ where $q=(4 \pi / \lambda) \sin \theta$ ( $\lambda$ is the wavelength and $2 \theta$ is the scattering angle).

The self-assembly of gold NPs in the epoxy composites was observed by transmission electron microscopy (TEM, $120 \mathrm{kV}$ microscope Tecnai G2 Spirit, FEI) and high-resolution transmission electron microscopy (HRTEM, $300 \mathrm{kV}$ microscope JEM 3010 , Jeol), provided with selected-area electron diffraction (SAED) and energy dispersive analysis of X-rays (EDAX). Ultrathin sections (50 $\mathrm{nm}$ thickness) were obtained by ultramicrotomy at room temperature. The air-polymer interface was 


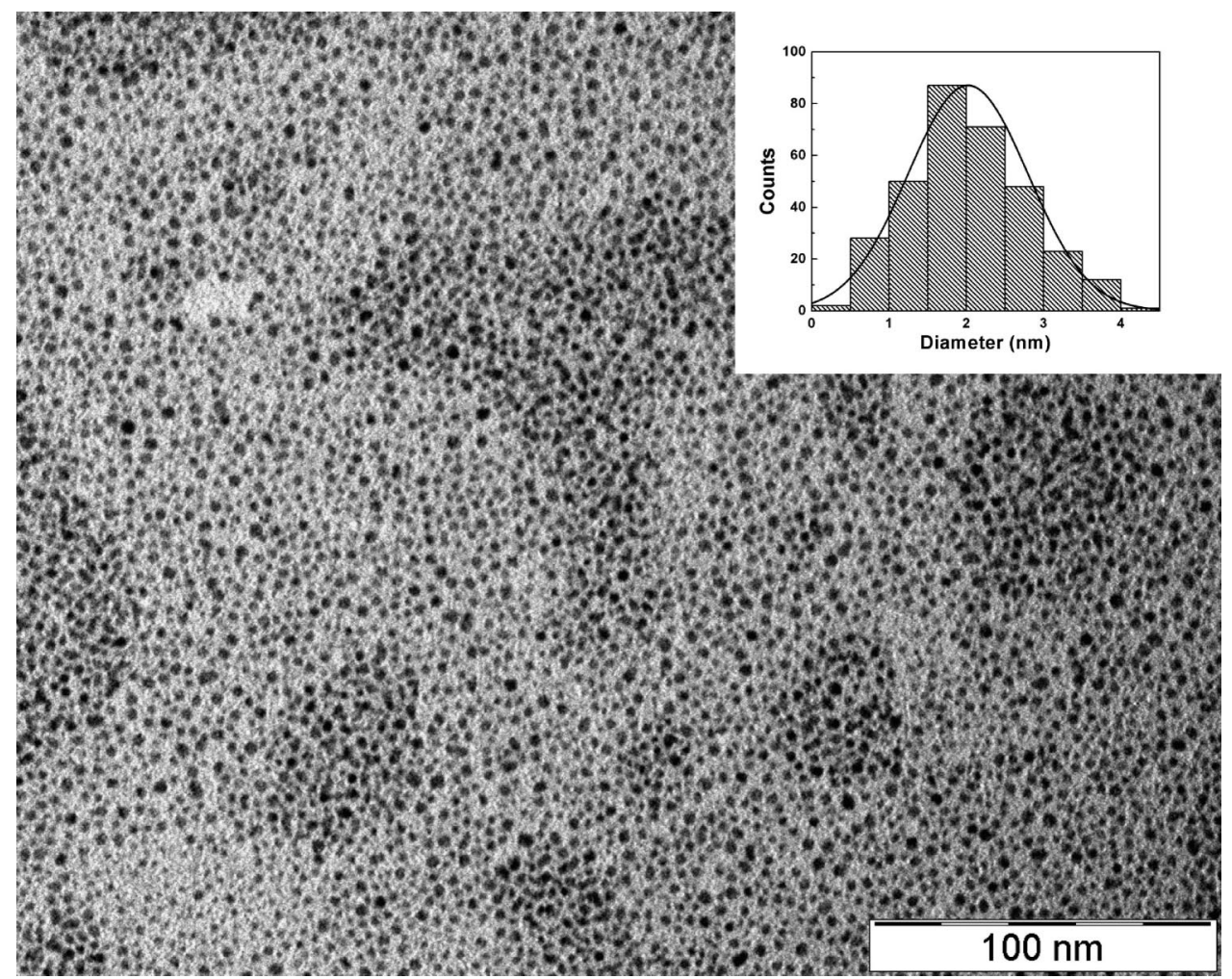

Figure 8. TEM image of the dodecanethiol-coated gold NPs. The inset shows the size distribution of the metallic core of the gold NPs.

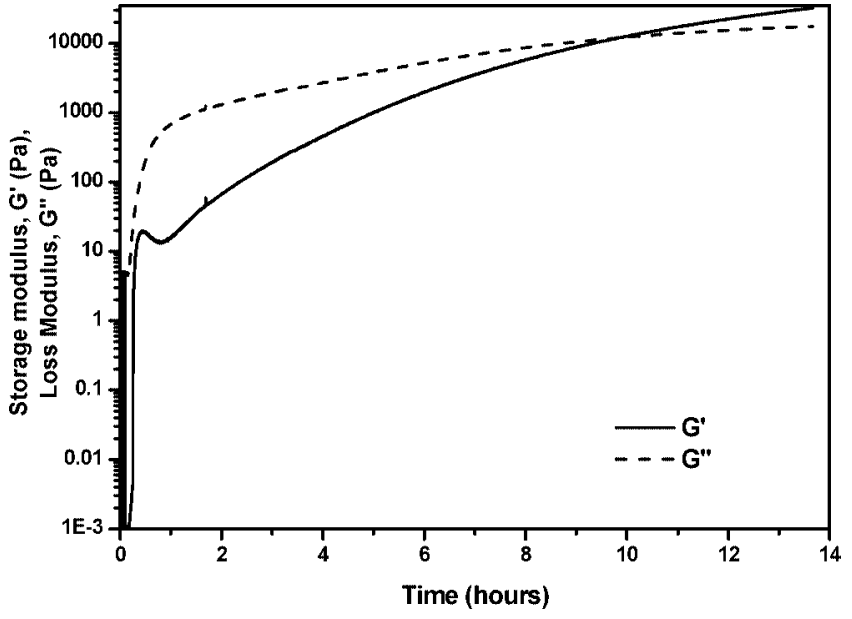

Figure 9. Evolution of the storage $\left(G^{\prime}\right)$ and loss modulus $\left(G^{\prime \prime}\right)$ during the heating at $100{ }^{\circ} \mathrm{C}$ of a DGEBA-DA solution containing $0.15 \mathrm{wt}$ $\%$ gold NPs.

also observed employing scanning electron microscopy (SEM, Jeol 6460) provided with an EDAX analyzer system (Genesis Spectrum V5.11). The device was operated at 10-15 V under low vacuum conditions $(48-51 \mathrm{~Pa})$.

\section{Results and Discussion}

Amphiphilic Polymer Generated by the Reaction of DA with DGEBA. Figure 2 shows the conversion of epoxy groups determined by NIR spectroscopy, as a function of reaction time at $100{ }^{\circ} \mathrm{C}$. A high conversion level $(\geq 0.95)$ was reached after $40 \mathrm{~min}$ and the complete disappearance of the epoxy peak was observed after about $2.5 \mathrm{~h}$ at $100{ }^{\circ} \mathrm{C}$. The product obtained after $3 \mathrm{~h}$ reaction at $100{ }^{\circ} \mathrm{C}$ was transparent, flexible, and very sticky at room temperature $\left(T_{\mathrm{g}}=10.4{ }^{\circ} \mathrm{C}\right)$. It was completely soluble in different solvents such as THF, acetone, DMF, toluene, dichloromethane, and chloroform.

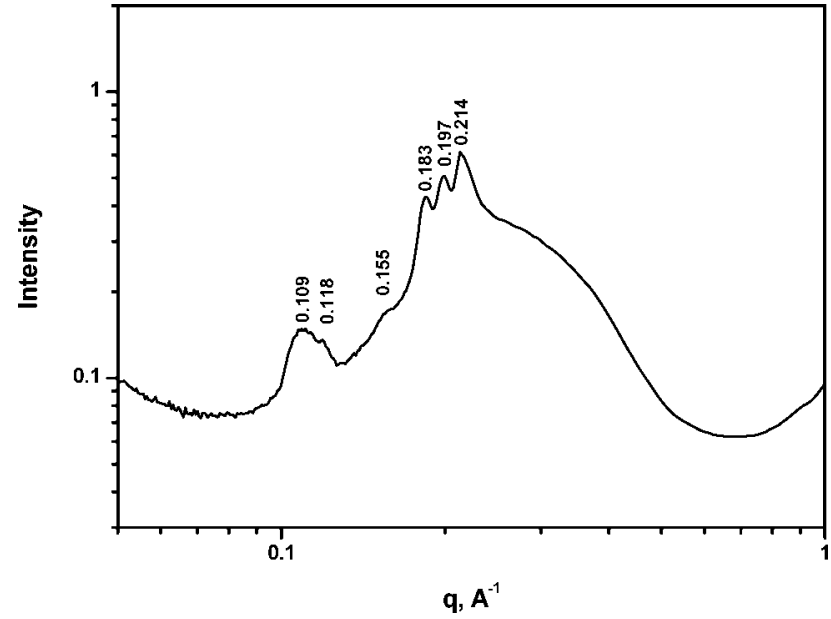

Figure 10. SAXS spectrum recorded at room temperature of a DGEBA-DA sample containing 0.15 wt $\%$ gold NPs after $14 \mathrm{~h}$ at $100{ }^{\circ} \mathrm{C}$.

The reaction between epoxy groups of DGEBA and $\mathrm{NH}$ groups of DA leads to a linear polymer. For stoichiometric formulations of DGEBA and monoamines, an ideal step-growth process was observed without any side reactions. ${ }^{34} \mathrm{~A}$ full conversion would lead to an infinite value of the number-average molar mass. The actual value is however limited by the following factors: (a) unavoidable deviations of exact stoichiometry, (b) incomplete conversion (asymptotic behavior to full conversion), and (c) formation of cyclic oligomers. Figure 3 shows the molar mass distribution obtained by SEC relative to polystyrene standards. Number and mass-average molar masses were $M_{\mathrm{n}}=16800 \mathrm{~g} / \mathrm{mol}$ and $M_{\mathrm{w}}=42000 \mathrm{~g} / \mathrm{mol}$. The series of small peaks present in the low-molar-mass range could be identified using MALDI-TOF MS. Peaks corresponding to the following oligomers were detected in the mass spectrum: $(\text { DGEBA-DA })_{2}+\mathrm{Na}^{+}$(experiment, 1072.4 Da; theory, 1074.5 

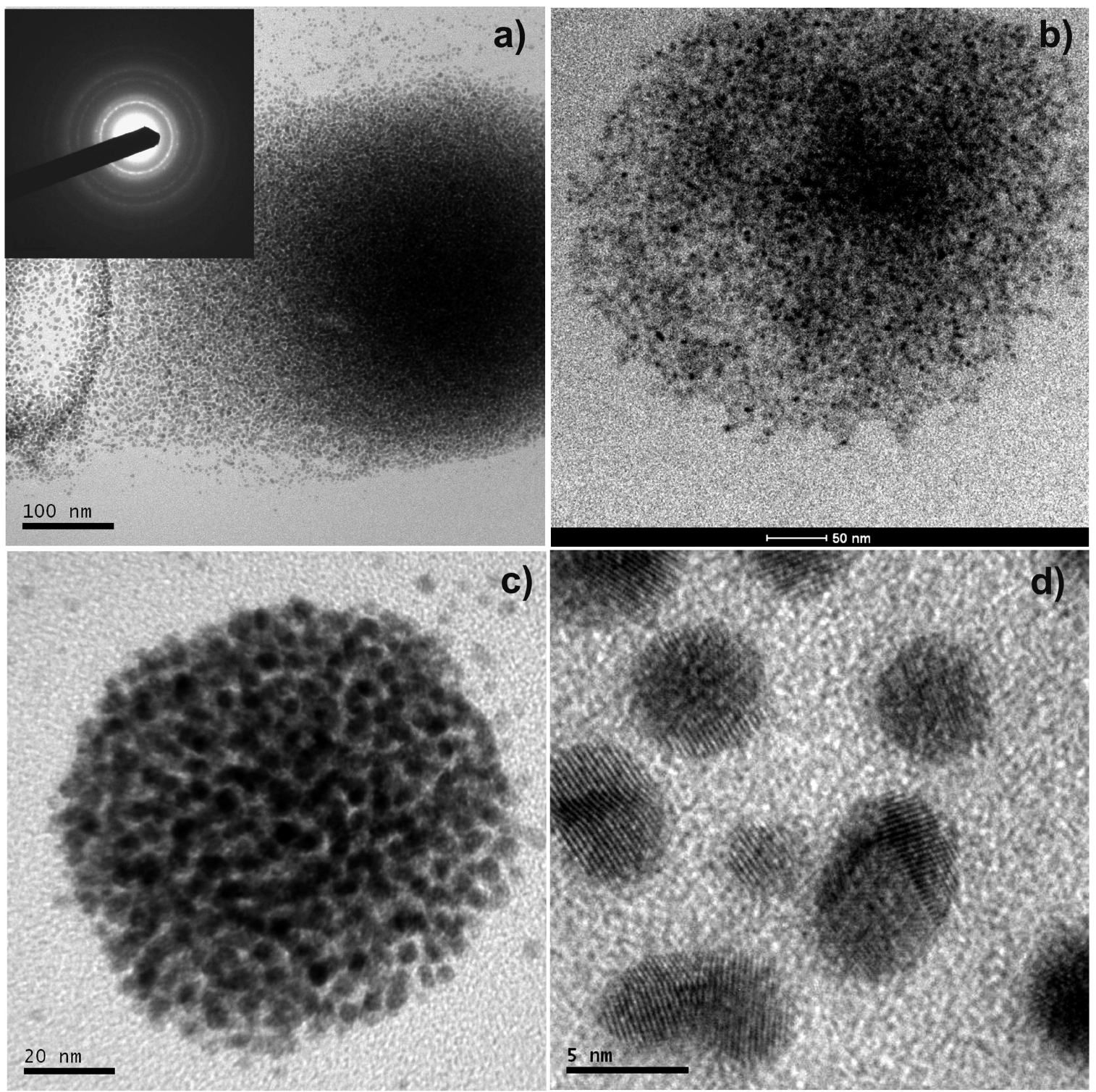

Figure 11. $(a-c)$ Representative TEM images of colloidal crystals constituted by gold NPs trapped in the epoxy matrix, and (d) HRTEM image showing the presence of crystalline planes in individual nanocrystals. The inset in (a) shows the SAED pattern of gold nanoparticles. The diffraction ring pattern is characteristic of polycrystalline gold.

Da; intensity, $1033 \mathrm{au}),(\mathrm{DGEBA}-\mathrm{DA})_{3}+\mathrm{Na}^{+}$(experiment, 1596.9 Da; theor.: 1600.3 Da, intensity: $332 \mathrm{au}$ ), (DGEBA-DA) $4+\mathrm{Na}^{+}$(exp.: $2122.1 \mathrm{Da}$, theor.: $2126.1 \mathrm{Da}$, intensity: $152 \mathrm{au}),(\text { DGEBA-DA })_{5}+\mathrm{Na}^{+}(\exp .: 2646.5 \mathrm{Da}$, theory, 2651.8 Da; intensity, $83 \mathrm{au}$ ). By taking into account the very high conversion of epoxy groups (the residual fraction of free epoxy groups was located in a range beyond the detection limit of NIR spectroscopy), and the absence of a peak corresponding to DGEBA-DA, the detected peaks can be assigned to cyclic species containing two to five DGEBA-DA units. The fraction of these species decreases sharply from the dimer (composed of 2 DGEBA and 2 DA units) to the pentamer. This follows the qualitative trend shown in Figure 3 and agrees with the decreasing probability of closing cycles when increasing the oligomer size. The mass of cyclic species predicted using PS standards is shifted to the high-molar-mass range (e.g., the peak of the dimer appears at 1390 Da compared to a theoretical value of $1049 \mathrm{Da}$ ). As the shift factor might be different for linear species that constitute the main fraction of the epoxyamine polymer, average molar masses were reported based on PS standards.
After a prolonged storage (about one month) at room temperature, the polymer synthesized during $3 \mathrm{~h}$ at $100{ }^{\circ} \mathrm{C}$ became insoluble in most solvents. A similar phenomenon was observed when the heating at $100{ }^{\circ} \mathrm{C}$ was performed during $14 \mathrm{~h}$. The polymer increased its $T_{\mathrm{g}}$ to $24^{\circ} \mathrm{C}$ and could only be dissolved in $p$-xylene at $135{ }^{\circ} \mathrm{C}$ after prolonged heating. The explanation of this behavior is related to the self-assembly of dodecyl chains, a process that occurs much more slowly than the polymerization reaction. This leads to the formation of a physical gel where the cross-links are formed by associations among dodecyl chains. In this way, the amphiphilic linear polymer generates a physical gel that could only be dissolved by destroying the association of hydrophobic chains using $p$-xylene at $135{ }^{\circ} \mathrm{C}$ (typical conditions used to dissolve polyethylene).

The nanostructuring process leading to a physical gel was followed by rheometry at $100{ }^{\circ} \mathrm{C}$. Figure 4 shows the evolution of the dynamic shear storage modulus $\left(G^{\prime}\right)$ during the first $2 \mathrm{~h}$ of reaction at $100{ }^{\circ} \mathrm{C}$. The first increase of the storage modulus can be associated to the polymerization reaction that occurs at a fast rate during this period. At about 36 min, when the epoxy 


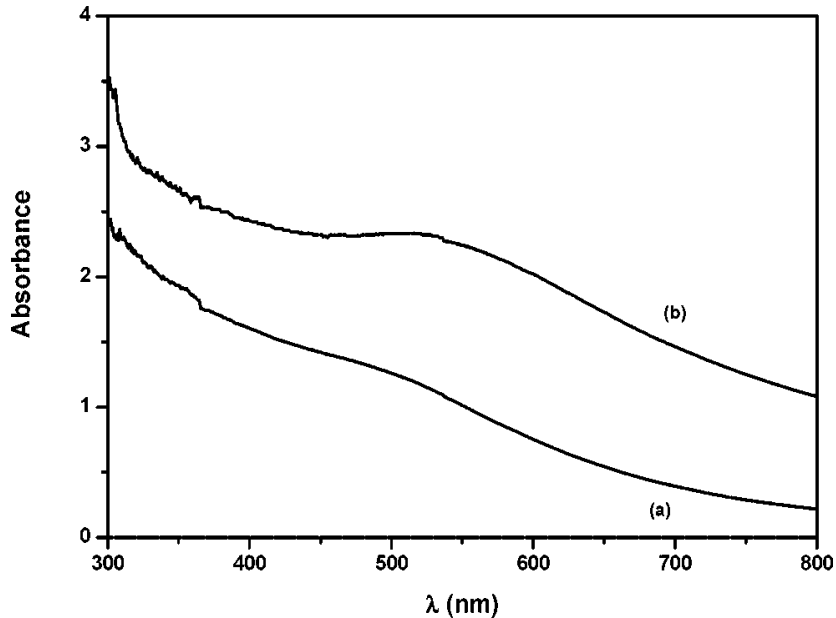

Figure 12. UV-visible spectra for (a) solution of as-synthesized gold NPs dissolved in THF and (b) gold NPs coalesced and self-assembled in the epoxy matrix.

conversion was close to 0.95 , a second process producing a fast increase of the storage modulus was observed. This second process corresponds to the nanostructuring of the amphiphilic polymer by the self-association of dodecyl chains. Therefore, polymerization and nanostructure formation are independent processes that take place one after the other, with a small overlapping at high conversions.

When the evolution of the system at $100{ }^{\circ} \mathrm{C}$ was followed for $14 \mathrm{~h}$, physical gelation could be observed. Figure 5 shows the evolution of the storage $\left(G^{\prime}\right)$ and loss modulus $\left(G^{\prime \prime}\right)$ during the prolonged heating at $100{ }^{\circ} \mathrm{C}$. At about $10.6 \mathrm{~h}, G^{\prime}$ surpassed $G^{\prime \prime}$, implying that a liquid-solid transformation took place. This corresponds to the onset of physical gelation produced by association of dodecyl chains (a precise determination of the gel point would require to obtain the condition where $\tan \delta=$ $G^{\prime \prime} / G^{\prime}$ becomes independent of frequency; however, this point must be close to the crossover of $G^{\prime}$ and $\left.G^{\prime \prime}\right) .^{35}$

After $14 \mathrm{~h}$ at $100{ }^{\circ} \mathrm{C}$, the same sample was stored for two days at room temperature, cooled to $-20{ }^{\circ} \mathrm{C}$, and scanned in the rheometer at $1{ }^{\circ} \mathrm{C} / \mathrm{min}$. Figure 6 shows the evolution of $G^{\prime}$ and $G^{\prime \prime}$ during the heating scan. The sharp decrease of the storage modulus at $30{ }^{\circ} \mathrm{C}$ corresponds to the glass-rubber transition of the amphiphilic gel. At about $150{ }^{\circ} \mathrm{C}$, a crossover between $G^{\prime}$ and $G^{\prime \prime}$ is again observed, implying that the material recuperates a liquid behavior. Therefore, clusters formed by dodecyl chains could be destroyed either by heating to $150{ }^{\circ} \mathrm{C}$ or by using $p$-xylene at $135^{\circ} \mathrm{C}$.

In order to get more information of the characteristic size of clusters formed by dodecyl chains, a SAXS spectrum of the sample heated for $14 \mathrm{~h}$ at $100^{\circ} \mathrm{C}$ was recorded at room temperature (Figure 7). A broad interference peak with a maximum at $q=0.265$ $\AA^{-1}$ was observed, corresponding to a characteristic length $d$ $=2 \pi / q=2.4 \mathrm{~nm}$. The broadness of this peak suggests that no regular order is present in the aggregates of dodecyl chains; DSC scans showed no evidence of crystallinity.

The characteristic distance observed in the SAXS spectrum lies in the range of values reported for tail-to-tail associations of dodecyl chains. ${ }^{36}$ A maximum distance of about $3.4 \mathrm{~nm}$ is observed when individual dodecyl chains exhibit all-trans conformations (extended chains). ${ }^{36,37}$ The distance is reduced when chains exhibit trans and gauche conformations of individual segments or when they are interdigitated. The identification of chains exhibiting all-trans conformations is characterized by the location of symmetric $\left(\mathrm{d}^{+}\right)$and antisymmetric $\left(\mathrm{d}^{-}\right) \mathrm{CH}_{2}$ stretching peaks in FTIR spectra, respectively, at 2846-2850 $\mathrm{cm}^{-1}$ and $2915-2918 \mathrm{~cm}^{-1}{ }^{38}$ For disordered chains, these

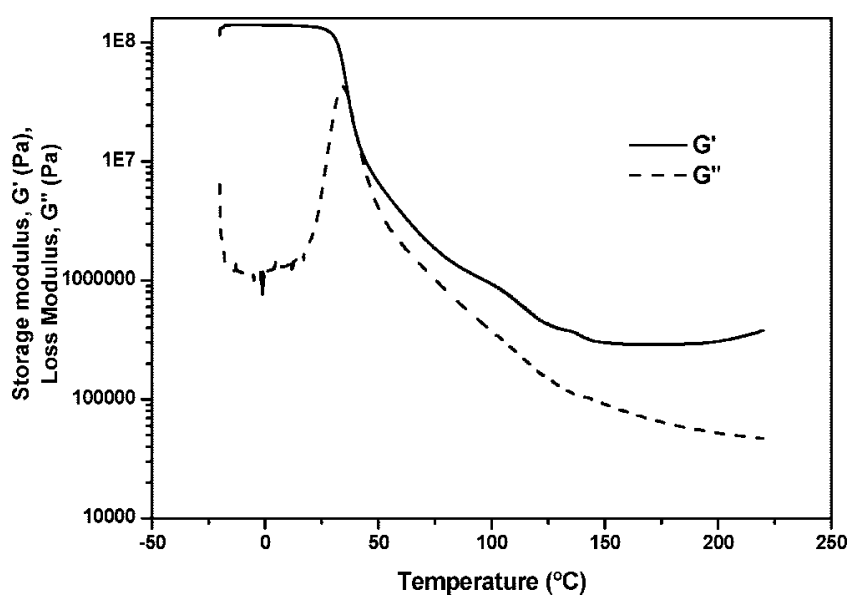

Figure 13. Evolution of the storage $\left(G^{\prime}\right)$ and loss modulus $\left(G^{\prime \prime}\right)$ during a thermal scan at $1{ }^{\circ} \mathrm{C} / \mathrm{min}$ of a sample containing $0.15 \mathrm{wt} \%$ gold NPs previously heated during $14 \mathrm{~h}$ at $100{ }^{\circ} \mathrm{C}$, stored for 2 days at room temperature, and cooled to $-20^{\circ} \mathrm{C}$.

peaks are shifted to $\approx 2856$ and $\approx 2928 \mathrm{~cm}^{-1} \cdot{ }^{38}$ MIR spectra were obtained in the course of the polymerization of DGEBA-DA at $100{ }^{\circ} \mathrm{C}$. The location of the symmetric $\mathrm{CH}_{2}$ stretching peak was shifted from $2848 \mathrm{~cm}^{-1}$ at $t=0$ to $2852.5 \mathrm{~cm}^{-1}$ after $14 \mathrm{~h}$ heating. The antisymmetric peak was shifted from $2919.4 \mathrm{~cm}^{-1}$ at $t=0$ to $2923.8 \mathrm{~cm}^{-1}$ after $14 \mathrm{~h}$ heating. Therefore, in the initial system, dodecyl chains were mostly present with extended conformations, but in the course of the polymerization/nanostructuring process some gauche conformations were generated. Changes in conformation together with the interdigitation of dodecyl chains may explain the resulting characteristic size of hydrophobic domains.

Summarizing these results, it was shown that the polymerization between DGEBA and DA was followed by the nanostructuring of the amphiphilic polymer by tail-to-tail association of dodecyl chains leading to a physical gel.

Self-Assembly of Gold Nanoparticles Induced by Polymerization. Figure 8 shows a TEM image of the as-synthesized dodecanethiol-coated gold NPs. The inset shows the size distribution of the Au cores with an average value of $2.0 \mathrm{~nm}$. The weight percentage of gold in the NPs was $78 \%$, as determined by thermogravimetry (the remaining $22 \%$ corresponds to the dodecanethiol chains).

Dodecanethiol-coated gold nanoparticles $(0.15 \mathrm{wt} \%)$ were stably dispersed in the DGEBA-DA precursors. Due to the compatibility between the dodecyl chains coating the NPs with those of DA, no evidence of phase separation was observed after prolonged storage times. However, during the polymerization/nanostructuring process this compatibility was lost.

The first indication of the presence of a phase separation process was obtained following the evolution of $G^{\prime}$ and $G^{\prime \prime}$ during prolonged heating at $100{ }^{\circ} \mathrm{C}$ (Figure 9). At about 30 min, when the conversion was higher than 0.9 , a sudden decrease of the storage modulus was observed. A similar behavior was observed at the time of phase separation of a thermoplastic-thermoset blend when the thermoplastic-rich phase is the dispersed phase. ${ }^{23}$ Blending gold NPs with the polymer precursors produced an increase in the storage modulus of the resulting solution. Phase separation of a NP-rich phase led to a temporal decrease of $G^{\prime}$, followed by a continuous increase due to the nanostructuring of the amphiphilic polymer. The formation of a physical gel took place at about the same time than for the neat polymer.

A SAXS spectrum recorded at room temperature for the material obtained after $14 \mathrm{~h}$ at $100{ }^{\circ} \mathrm{C}$ is shown in Figure 10. Overlapped with the broad scattering peak of dodecyl aggregates 


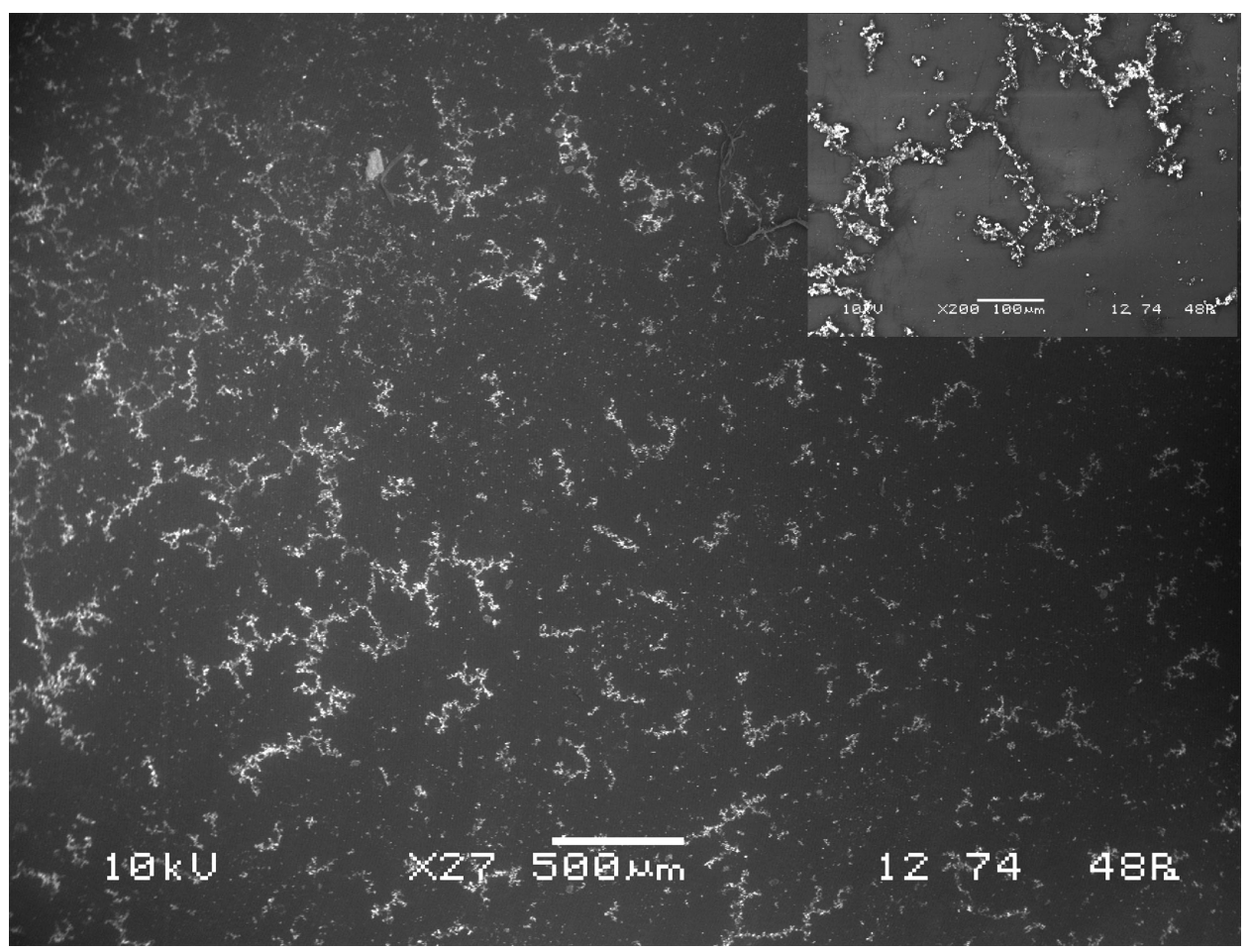

Figure 14. SEM image of the material containing gold NPs at the air-polymer interface. The inset is a magnification of a selected region of the same sample.

of the amphiphilic polymer at $q=0.265 \AA^{-1}$, there appeared a new series of scattering peaks assigned to a crystalline phase formed by gold NPs. The high number of diffraction peaks and their low widths is an indication of a well-defined crystalline order. The location of these peaks corresponds to a 3D hexagonal close-packed array (HCP), ${ }^{39}$ where the sequence of peaks in $q_{0}$ units is expected at $1,1.06,1.13,1.46,1.73,1.88$, $2, \ldots$ Taking $q_{0}=0.106 \AA^{-1}$ leads to the following series of expected peaks (in $\AA^{-1}$ ): $0.106,0.112,0.120,0.155,0.183$, 0.199 , and 0.212 that agrees almost exactly with experimental values (the first three peaks are overlapped).

The presence of colloidal crystals formed by gold NPs was confirmed using TEM and HRTEM. Spherical aggregates of gold NPs with a broad size distribution comprised between tens and hundreds of nanometers, randomly dispersed in the epoxy matrix, were observed. Figure $11(\mathrm{a}-\mathrm{c})$ shows representative images of such crystals. Individuality of nanoparticles in the aggregates was preserved as a result of the protecting action of thiol chains. Both SAED (inset in Figure 11a) and EDAX confirmed the presence of crystalline gold NPs as building units of the colloidal crystal. Note that there are two levels of crystalline organization: one at the nanoparticle level and the other one at the level of spherical aggregates, exhibiting an $\mathrm{HCP}$ array (at the level of the nanoparticles, the elements that are organized in the crystal structure are gold atoms, and at the level of the HCP crystal, the elements that are organized are the NPs). The crystalline planes of individual gold nanoparticles are clearly observed in Figure 11d.

The construction of three-dimensional structures formed by gold NPs has been reported by several authors. ${ }^{40-44}$ However, this is to our knowledge the first report on the formation of large colloidal HCP crystals by the self-assembly of gold NPs induced by polymerization.

A striking feature of the present system is the size of the gold NPs present in the crystalline spherical aggregates. The center-to-center distance of spheres packed in the HCP array is given by $a=(4 / 3)^{1 / 2}\left(2 \pi / q_{0}\right)=6.84 \mathrm{~nm} .{ }^{39}$ Discounting a distance of about $1.5-2 \mathrm{~nm}$ for the tail-to-tail association of dodecyl chains $^{19,45}$ leads to a diameter of about $5 \mathrm{~nm}$ for gold NPs present in the crystalline aggregates. This agrees with the diameters estimated from HRTEM images. However, as shown in Figure 8 there were no particles of this size in the initial distribution. Moreover, the high definition of the scattering peaks obtained in SAXS experiments (Figure 10) indicates that HCP colloidal aggregates were formed by NPs with a narrow size distribution. To reconcile these experimental observations it is necessary to assume that a particular coalescence process leading to a narrow size distribution of gold NPs took place before crystallization. The formation of NPs-rich domains by polymerization-induced phase separation should favor the possibility of producing coalescence.

A procedure leading to a controlled coalescence of gold NPs in solution has been described in the literature. ${ }^{45,46}$ Basically, it requires a heating strategy producing desorption of dodecanethiol chains followed by coalescence of the nude gold NPs and re-adsorption of dodecanethiol chains to stabilize the larger particles. This process requires a pre-concentration of the solution of NPs (in our case this step is produced by the polymerization-induced phase seperation of a NPs-rich phase), and the presence of hydrophobic chains in the solvent providing the environment for stabilizing the nude NPs during the evolution process (in our case this is provided by DA units). This heating treatment strategy was proposed for producing monodispersed and highly faceted NPs from solutions of preformed smaller particles. ${ }^{45,46}$ For the particular conditions employed by Maye et al., ${ }^{45}$ dodecanethiol-coated gold NPs with an average core size of $2.0 \mathrm{~nm}$ ( $80 \%$ of the population in the $1.5-2.5 \mathrm{~nm}$ range) were converted into NPs with an average core size of $5.2 \mathrm{~nm}(90 \%$ of the population in the $4.7-5.7 \mathrm{~nm}$ range), a similar result as to the one obtained in the present study. Upon solvent evaporation, these almost monodispersed NPs exhibited 2D and 3D organization features. ${ }^{45}$

Free thiol groups of dodecanethiol chains desorbed from the gold surface might react with residual epoxy groups if the thiol is partially converted to $\mathrm{S}^{-}$ions in the presence of amine species. ${ }^{47-49}$ However, at the time where phase separation was 
evidenced by rheometry, the conversion of epoxy groups was higher than $90 \%$. Therefore, even if some thiol-epoxy reaction can occur, its extent should be very low.

Another evidence of the coalescence of NPs is obtained from the surface plasmon (SP) resonance bands of the as-synthesized population of gold NPs and the population of gold NPs trapped and self-assembled in the epoxy matrix (Figure 12). The spectrum of the initial population of NPs displays an identifiable but weak SP band envelope around $515 \mathrm{~nm}$ (curve a in Figure 12). The shape and position of this band is in agreement with those previously reported for gold NPs of similar sizes. ${ }^{4,50}$ Coalescence of NPs produced an increase in the intensity of the SP band that is indicative of an increase in core size within the size range comprised between 2 and $6 \mathrm{~nm} .^{45,50,51}$ Coupled to the increase in intensity, a broadening of the absorption spectra to the red was observed that can be ascribed to the formation of aggregates of gold NPs. ${ }^{52}$

Colloidal crystals trapped in the epoxy matrix should be stabilized by interactions of dodecyl chains coating gold NPs located at the periphery of the crystal with those of DA units covalently bonded in the epoxy polymer. The existence of these interactions can be inferred from the evolution of the storage and loss modulus during a thermal scan (Figure 13). The material does not exhibit the solid-liquid transformation at 150 ${ }^{\circ} \mathrm{C}$ observed for the neat epoxy (Figure 6). Although small clusters of dodecyl chains could still be destroyed, the large surface of colloidal crystals produces a high number of dodecyl-dodecyl interactions with the matrix that cannot be simultaneously unzipped by increasing temperature. Therefore, the material with the dispersion of colloidal crystals behaves as a cross-linked rubber above the glass transition.

Partitioning and irreversible adsorption of large colloidal particles at the air-polymer interface might be expected. ${ }^{53}$ The reason is that the energy $(E)$ required for removing the particle from the interface to the polymer bulk increases with the square of its radius $(r):^{53}$

$$
\mathrm{E}=\pi r^{2} \gamma \alpha \beta(1-\cos \theta)^{2}
$$

Assuming a contact angle $\theta \approx 90^{\circ}$ and an interfacial tension $\gamma_{\alpha \beta} \approx 30 \mathrm{mN} / \mathrm{m}$ gives $E / k T \approx 2.9 \times 10^{4}$ for colloidal particles of $r=40 \mathrm{~nm}$ (this is the approximately the size of the colloidal crystal shown in Figure 11c; the attachment energy of larger crystals as those shown in panels a and b of Figure 11 is much higher, as $E$ increases with the square of the particle size; the thermal energy was calculated at $373 \mathrm{~K}$ corresponding to the polymerization temperature).

One consequence of the very high energy of attachment of the large gold colloidal crystals to the air-polymer interface, relative to the thermal energy $k T$, is that their adsorption might be considered irreversible. Therefore, a large partitioning of these particles at the interface can be expected. This is clearly evidenced in SEM images of the air-polymer interface, showing the presence of clusters of gold NPs (Figure 14). Diffusionlimited-aggregation models account for the highly ramified fractal structures. ${ }^{54,55}$ The concentration of gold aggregates at the interface can be further increased by increasing the surface/ volume ratio of the sample (e.g., decreasing the thickness of the film). This can give rise to percolating fractal structures that can find useful applications.

\section{Conclusions}

The polymerization between DGEBA and DA was followed by the nanostructuring of the amphiphilic polymer by tail-totail association of dodecyl chains leading to a physical gel. The polymer exhibited a glass transition of $24{ }^{\circ} \mathrm{C}$ and physical-gel behavior above $T_{\mathrm{g}}$. Dodecanethiol-coated gold NPs were stably dispersed in the DGEBA-DA precursor due to the presence of dodecyl chains in both components. However, a polymerizationinduced phase separation produced NP-rich domains. Desorption of dodecanethiol chains followed by coalescence of the nude gold NPs and readsorption of dodecanethiol chains produced a narrow distribution of larger gold NPs. This was followed by crystallization into HCP arrays. A random dispersion of colloidal crystals with sizes in the range of tens to hundreds of nanometers was present in the amphiphilic epoxy matrix. Colloidal crystals were stabilized by dodecyl-dodecyl interactions among the organic coating of NPs and DA units of the epoxy matrix. Partitioning and irreversible adsorption of large colloidal particles at the air-polymer interface were observed, leading to highly ramified fractal structures. This was explained by the high energy needed to remove large colloidal particles attached at the air-polymer interface. The DGEBA-DA precursor may be useful to produce self-assemblies of different types of NPs coated by alkyl chains.

Acknowledgment. We acknowledge the financial support of the National Research Council (CONICET, Argentina), the National Agency for the Promotion of Science and Technology (ANPCyT, Argentina, project PICT03-14738), the University of Mar del Plata (Argentina), the Ministry of Science and Technology (Spain, projects MAT2005-07554-C02-01 and PGIDIT03PXIC20907PN), and the Grant Agency of the Academy of Sciences of the Czech Republic (project IAA 400500701). C.E.H. gratefully acknowledges the European Commission for financial support (IIF Marie Curie fellowship, MIF2-CT-2006-021689).

\section{References and Notes}

(1) Alivisatos, A. P. Science 1996, 271, 933.

(2) Collier, C.; Vossmeyer, T.; Heath, J. Annu. Rev. Phys. Chem. 1998, 49, 371.

(3) Weller, H. Philos. Trans. R. Soc. London Ser. A 2003, 361, 229.

(4) Liz-Marzán, L. M.; Kamat, P. V.; Eds. Nanoscale Materials; Kluwer: Boston, 2003.

(5) Pileni, M. P. Nanocrystals Forming Mesoscopic Structures; WileyVCH: Weinheim, 2005.

(6) Shenhar, R.; Norsten, T. B.; Rotello, V. M. Adv. Mater. 2005, 17, 657.

(7) Vaia, R. A.; Maguire, J. F. Chem. Mater. 2007, 19, 2736.

(8) Luo, J.; Jones, V. W.; Han, L.; Maye, M. M.; Kariuki, N. N.; Zhong, C. J. Phys. Chem. B 2004, 108, 9669.

(9) Balasz, A. C.; Emrick, A.; Russell, T. P. Science 2006, 314, 1107.

(10) Uhlenhaut, D. I.; Smith, P.; Caseri, W. Adv. Mater. 2006, 18, 1653.

(11) Lin, Y.; Skaff, H.; Emrick, A.; Dinsmore, A.; Russell, T. P. Science 2003, 299, 14-226.

(12) Lin, Y.; Skaff, H.; Boker, A.; Dinsmore, A.; Emrick, T.; Russell, T. P. J. Am. Chem. Soc. 2003, 125, 12690.

(13) Reincke, F.; Hickey, S.; Kegel, W.; Vanmaekelbergh, D. Angew. Chem., Int. Ed. 2004, 43, 458.

(14) Duan, H.; Wang, D.; Sobal, N.; Giersig, M.; Kurth, D.; Möhwald, H. Nano Lett. 2005, 5, 949.

(15) Glogowski, E.; He, J.; Russell, T. P.; Emrick, T. Chem. Commun. 2005, 4050.

(16) Reincke, F.; Kegel, W.; Zhang, H.; Nolte, M.; Wang, D.; Vanmaekelbergh, D.; Möhwald, H. Phys. Chem. Chem. Phys. 2006, 8, 3828.

(17) Wang, J.; Wang, D.; Sobal, N. S.; Giersig, M.; Jiang, M.; Möhwald, H. Angew. Chem., Int. Ed. 2006, 45, 7963.

(18) Wakabayashi, A.; Sasakawa, Y.; Dobashi, T.; Yamamoto, T. Langmuir 2006, 22, 27-9260.

(19) Bigioni, T. P.; Lin, X. M.; Nguyen, T. T.; Corwin, E. I.; Witten, T. A.; Jaeger, H. M. Nat. Mater. 2006, 5, 265.

(20) Zhang, X.; Shi, F.; Yu, X.; Liu, H.; Fu, Y.; Wang, Z.; Jiang, L.; Li, X. J. Am. Chem. Soc. 2004, 126, 3064.

(21) Echte, A. In Rubber-Toughened Plastics; Riew, C. K., Ed.; American Chemical Society: Washington, DC, 1989; p 15.

(22) Riew, C. K.; Gillham, J. K. Rubber-Modified Thermoset Resins; American Chemical Society: Washington, DC, 1984.

(23) Pascault, J. P.; Williams, R. J. J. In Polymer Blends: Formulation; Paul, D. R., Bucknall, C. B., Eds.; Wiley: New York, 2000; Vol. 1, p 379.

(24) Drzaic, P. S. Liquid Crystal Dispersions; World Scientific: Singapore, 1995.

(25) Hoppe, C. E.; Galante, M. J.; Oyanguren, P. A.; Williams, R. J. J. Macromolecules 40. $200437,5352$. 
(26) Zucchi, I. A.; Galante, M. J.; Williams, R. J. J. Eur. Polym. J. 2006, 42,815 .

(27) Pascault, J. P.; Williams, R. J. J. In Micro- and nanostructured multiphase polymer blend systems; Harrats, C.; Thomas, S.; Groeninckx, G., Eds.; CRC Press-Taylor and Francis: Boca Raton, FL, 2006; p 359.

(28) Soulé, E. R.; Borrajo, J.; Williams, R. J. J. Macromolecules 2007, 40, 8082 .

(29) Zucchi, I. A.; Galante, M. J.; Williams, R. J. J.; Franchini, E.; Galy, J.; Gérard, J. F. Macromolecules 2007, 40, 1274.

(30) Brust, M.; Walker, M.; Bethell, D.; Schiffrin, D. J.; Whyman, R. Chem. Commun. 1994, 801.

(31) Min, B. G.; Stachurski, Z. H.; Hodgkin, J. H.; Heath, G. R. Polymer 1993, 34, 3620.

(32) Poisson, N.; Lachenal, G.; Sautereau, H. Vib. Spectrosc. 1996, 12, 237.

(33) Zucchi, I. A.; Galante, M. J.; Williams, R. J. J. Polymer 2005, 46, 2603.

(34) Klee, J.; Hörhold, H. H.; Tänzer, W. In Crosslinked epoxies; Sedláček, B., Kahovec, J., Eds.; de Gruyter: Berlin, 1987; p 47.

(35) Pascault, J. P.; Sautereau, H.; Verdu, J.; Williams, R. J. J. Thermosetting Polymers; Dekker: New York, 2002.

(36) Shimojima, A.; Kuroda, K. Chem. Rec. 2006, 6, 53.

(37) Romeo, H. E.; Fanovich; María, A.; Williams, R. J. J.; Matjka, L.; Plestil, J.; Brus, J. Macromolecules 2007, 40, 1435.

(38) Wang, R.; Baran, G.; Wunder, S. L. Langmuir 2000, 16, 6298.

(39) Soni, S. S.; Brotons, G.; Belour, M.; Narayanan, T.; Gibaud, A. J. Phys. Chem. B 2006, 110, 15157.
(40) Kimura, K.; Sato, S.; Yao, H. Chem. Lett. 2001, 372.

(41) Stoeva, S. I.; Klabunde, K. J.; Sorensen, C. M.; Dragieva, I. J. Am. Chem. Soc. 2002, 124, 2305.

(42) Prasad, B. L. V.; Stoeva, S. I.; Sorensen, C. M.; Klabunde, K. J. Langmuir 2002, 18, 7515.

(43) Sato, S.; Yao, H.; Kimura, K. Physica E 2003, 17C, 521.

(44) Wang, S.; Sato, S.; Kimura, K. Chem. Mater. 2003, 15, 2445.

(45) Maye, M. M.; Zheng, W.; Leibowitz, F. L.; Ly, N. K.; Zhong, C. J. Langmuir 2000, 16, 490.

(46) Maye, M. M.; Zhong, C. J. J. Mater. Chem. 2000, 10, 1895.

(47) Danehy, J. P.; Noel, C. J. J. Am. Chem. Soc. 1960, 82, 2511.

(48) TanakaY. M. In Epoxy Resins Chemistry and Technology; May C. T., Ed.; Dekker: New York, 1973; p 135

(49) Kamon, T.; Furukawa, H. Adv. Polym. Sci. 1986, 80, 173.

(50) Hostetler, M. J.; Wingate, J. E.; Zhong, C. J.; Harris, J. E.; Vachet, R. W.; Clark, M. R.; Londono, J. D.; Green, S. J.; Stokes, J. J.; Wignall, G. D.; Glish, G. L.; Porter, M. D.; Evans, N. D.; Murray, R. W. Langmuir 1998, 14, 17.

(51) Alvarez, M. M.; Khoury, J. T.; Schaaff, T. G.; Shafigullin, M. N.; Vezmar, I.; Whetten, R. L J. Phys. Chem. B 1997, 101, 3706.

(52) Hussain, I.; Wang, Z.; Cooper, A. I.; Brust., M. Langmuir 2006, 22, 2938.

(53) Binks, B. P. Curr. Opin. Colloid Interface Sci. 2002, 7, 21.

(54) Witten, T. A.; Sander, L. M. Phys. Rev. Lett. 1981, 47, 1400.

(55) Meakin, P. Phys. Rev. Lett. 1983, 51, 1119.

\section{MA800457W}

